\title{
Investigating the Internal Factors of Organization Affecting the Bank's Risk
}

\author{
Shahram Aminzadeh ${ }^{1}$, Mehdi Adibpour ${ }^{1 *}$ \\ ${ }^{I}$ Department of Economics, FiroozkoohBranch, Islamic Azad University, Firoozkooh, Iran.
}

\begin{abstract}
In different banks of the country some studies have been done, however, this study investigates the effective factors on nonperforming assets and the credit risk of loans in Melli bank.Population of the study, are legal and real customers inMelliBank of Iran on northern branches of Tehran during the years 1386-1394, and 100 samples were selected and evaluated by stratified random sampling method. To identify factors influencing credit risk, logistic regression was used.Based on the results of the study, and the total significance of regression by the use of LR statistic, independent variables such as collateral, the amount of collateral, the type of legal entity or individual customers, the degree of branch and the interest rate have a significant relationship with the dependent variable (deferred facilities and bank loans) and the duration of the repayment doesn't have a significant relationship with the dependent variable. The results in addition to imply affirmation of economic and financial theories regarding effective factors on credit risk, indicate that effective factors on credit risk of legal and real customers inMelliBank of Iran have a lot in common with the effective factors on credit risk of legal and real customers in other banks.
\end{abstract}

Keywords: Credit risk, logistic regression, nonperforming assets, Melli Bank of Iran

\section{Introduction}

In this study, we considered the internal factors of organization affecting the bank's risk in Melli bank in northern branch of Tehran, to prevent the emergence of new nonperforming assets, in order to optimal resource utilization in different economic sectors andincreasing the efficiency and dynamism of the banking network by using logistic regression analysis.

Due to the development and dynamics of the credit industry, although demand for credit,increased competition and the emergence of new channels in modern economy,has created new opportunities for financial institutions, but has also created some threats. So that, the need for new techniques and tools to survive in this system is clearly felt.

In recent years, one of the most important challenges facing the banking system, has been growing trend of nonperforming assets, and it has become a serious problem for the banking system of country, and due to the centrality of banks in economy of the country (monetary and financial market), and having a major part of liquidity in the banks of country it has become a national challenge and concern.In economies in which nonperforming assets of banks produce a substantial volume of liquidity of the country, to avoid the dangers of it, you need to find an appropriate solution. A solution which be applicable with the existing conditions and at the same time adapt an approach for the prevention of new claims and then organizing the existing conditions (Mousavi, 2010, p. 2).

Banks are trying to grant facilitiesto persons that have low risk and have appropriate coverage in the interest rate of received facilities. Providing optimum financial facilities is considered one of the most important activities of the banking system. Accordingly, in many countries, most banks have a separate and special unit for credit analysis, which aims to minimize risk through credit risk management.A list of factors about the applicant's bank facilities should be determined, such as his credit in the past (generally is defined by the credit rating agencies), the applicant's wealth, fluctuations of his profit, and whether in contract, facilities, collateral will be included or not? And based on these information the amount of risk possibility of customer default will be estimated (Mehrara, 2011, p.3).

The main and important issues considered in the allocation of bank resources are to examine and evaluate customer's risk and facilities of the recipients.Lack of information and access to actual data of customers is one of the most important intensifying credit risk factors. The possibility of non-repayment or delayed payment of principal and interest of granted facilities from banks is called credit risk (Fallah Shams $\&$ Tehrani, 2005).

The definition of credit risk by the Banking Supervision Committee on banking of International Settlements Bank (Basel) states:The credit risk is the possibility of shortcomings by the borrower, or the other party of the bank in performing their obligations according to the commitments.In other words, uncertainty about receiving future earnings of the investment is called risk. 
One of the best investment principles in all fields is that, the risk of investment should be commensurate with its efficiency. Always, there is a direct relationship between the performances of banking system in each country with that country's economical development, countries that have an efficient model in allocating the investment to different economical sectors, will have more economical progress and consequently social welfare.The banking system of the country can help to the creation of the social welfare, by the use of limited resources which are collected properlyand by preventing non-repayment of dealers,the bank will be benefited and also will be helpful in the general welfare of the society. This needs the appropriate assessment and investigation of borrowers which relates to the effective internal factors of organizations affecting bank's risk.

For each economical entities' profit, the place of selling goods or services is used for customers. In the meantime, banks will be benefited by providing diverse credit packages and producing facilities for customers, the only difference is that in banks and credit institutions, if the supplied goods (money) didn't return, no profit can be gained but it cause to the losses and bankruptcy. This conditions that these institutions are faced with, is a phenomenon known as credit risk or default risk and identifying customers and their ability to restore their sources is very important. From the perspective of banking system, good customer refers to the customer who uses the received facilities in the requested economical sector, and in the appropriate time he would be able to return the received facilities to the banking system, allocation of optimal financial resources in any financial institution, including banks is their major source of profit, but the big risks are related with decisions in this area, so evaluating and investigation of credit risk has particular importance.For most banks, loans are the largest and most obvious source of credit risk (Gambera, 2000).

Asymmetric information about the customer, including the information of borrower about himself which is more complete and careful than the information the lender holds about him and inappropriate choice causes this risk. This happens when banks due toweaknesses in identifying good customers, give their credit to customers who aren't competent and they don't have the ability of returning the received facilities fully and comprehensively in the appropriate time. And moral hazard, which indicates the lack of customers' commitment to the provisions of the contract,arises after receiving of the credits of the bank by customers (Armashi, 2011, p.7). In other words, each applicant for a loan or credit, can simply compare credit products of different banks, offered interest rates and credit conditions in granting credit products and easily do the most profitable choice.But the banks are actually uncertain in choose of customers for credit granting and it cause to the wrong choice (KokabiDelavar, 2013).So, now the majority of Iranian banks are face withresource reserves as nonperforming assets and regarding to the increasing trend of these nonperforming assets, the power of credit giving by banks and eventually earning power will be reduced. So identifying the effective internal factors of organization on bank's riskis very important,these factors can be controlled and mostly are related to the internal management of financial institutions. It's important because it can prevent from the loss of defaults in loans and banking crisis.

An important issue in the monetary and banking system, is how to mobilizing financial resources and then allocate and distribute it in different economical sectorsand between economic agents as well as existing routes in which the volume of the existing money enters into the economical system and circulates in it.According to the duties of the banking system in the mobilizing of financial resources and proper allocation of it in the economical system, whatever the banking system operates more efficiently, in mobilizing financial resources and allocating them in a competitive environment, thenproduction costs will decrease, and the quality of productions, employment and economical growth can be improved. Otherwise, inefficiency of the banking system in mobilizing and allocating financial resources leads to the waste of resources and fueling economic downturn (Ramezani, 2006)

The main task of banks is mediating the funds, this means that on the one hand they received funds from depositors, and on the other hand, the funds are paid in the form of facilities to customers.Holders of surplus funds, with depositing in the banks, actually lend own funds to the bank and receive a certain interest rate. Applicants of facilities in return of payment, borrow certain interest from banks. It is natural that the difference between the paid interest to depositors and the received profit from borrowers of facilities, comprises the profit of bank (Yadani\&Dehnavi, 2005).

According to the regulations governing and supervising banking system, the amount of nonperforming assets and expiring of time shall not exceed five per cent of the total balance of each bank facilities, because, otherwise the bank credit situation is considered critical.In recent years, we have witnessed dramatic growth in nonperforming assets of banking system, and it shows that the bank wasn't actually successful in the main task of the intermediary and had gone wrong.

At the time of deciding about granting facilities, the bank's responsibility isn't only the recognition of the moral and ethical responsibility of applicants to ensure that they adhere their commitments, but also expertly studies should be done to ensure the technical,economical and financial feasibility of the transaction subject (Heydarifar, 2011, p.2). 
The existence of nonperforming and expiring time, major financial resources, financial statements of banks and the consequences of depriving the bank from their finances, makesnecessarycreating an appropriate mechanism for timely repayment of the granted facilities (Tarfi, 2006, p.44). After the loan is received or accepted, the borrower may seek riskier projects to earn high efficiency, and in practice it arises the credit risk faced by banks (Yenpao, 2009).

So here the duty of the bank's senior managers will be more outstanding, so with their good management and control of effective internal factors of organizations on bank's risk, and their special wisdom and training good powers could reduce bank's risk and have adequate surrounding on financial market. In this competitive market, they do not lose customers, so they do not have high-risk, benefit both themselves and their customers.

Considering the customer and market is one of the most prominent milestones in the activities of banks which along with other measures that are agreed, provide the basis of growth and development in banks (Khavari, 2007).Also, in most cases, facilities have been turned into nonperforming assets, when there isn't enough recognition and strict validation weren't done for different reasons in the time of granting or not obtaining sufficient collateral.

From a variety of clients who are effective in nonperforming assets, beneficiaries can be noted. In many cases, a person with the establishment of several institutions and companies with different titles (Under the name of different companies)taking loans from the banks, while the recipient of facility is the same person, and because of that person's inability to pay debts,each of the various companies this person has established, itself becomes a separate debtor of claims. When bank interest is high, in the time of debt repayment and after passing a long time after expiring time conditions will be unpleasant for debtors (due to the increase in the amount of committed funds or delayed compensation).But many debtors are prepared to afford delayed penalty of loans and use their capital in the market, so by calculating the difference between market interest rates and interest rates of banks, they pay delayed penalties,but ultimately using this money in the market are of utmost interest.During the operation, this is the bank or financial institution that will be affected, its their right to receive a few percent of fines and apparently much more money than customer, but if the bank receives that fund resource timely, it could give that fund to other customer with complete interestand gains more profit. Further, some human factors looking for bank claims and collection of receivables in legal departments, which has cost for the institution. With regard to the issues raised and most frequently "refers to the internal factors that will be effective in deferred,investigation, pathology and considering causes of receivables and delay in repayment of loans in the banking system is crucial and in this study, we intend to examine it.

\section{Literature Review}

Vonegna and Witor (2013), examined the role of effective factors on improvement of loan repayment by potato farmers in Ghanawith probity model. Based on the obtained results, factors such as age, education level, experience, supervision and off-farm income had a positive effect on the performance of loan repaymentand gender and marital status have a negative impact on repayment performance.

Sylvester et al (2013), examined loan repayment performance of novice producers and processors of palm oil in Nigeria by using multiple regressionmodel.The results showed that, the size of loans affected by experience of processors, annual gross income and investment rates, also, the asset turnover ratio and the distance between lending place and home, are key factors in loan repayment rate.

Mahmoudi (2013), in his study entitled "investigating effective factors in non-repayment of granted quick yielding facilities in the branches of Melli bank of Shahrekord, stated:

Various factors affect the non-repayment of bank loans, and by identifying these factors grounds can be provided for reducing and controlling of credit risk in banks, and in the process of credit granting some improvements will be gained. The aim of this study was investigating effective factors in non-repayment of granted quick yielding facilities in the branches of Melli bank of Shahrekord during the years 2006-2010, and providing administrative solutions to improve the collection of receivables in the future. This research was a descriptive survey which was conducted using researcher made questionnaire. The population of the survey, were all staff and experts in branches ofMelli bank of Shahrekord.By using Cochran formula and simple random sampling, 140 person were selected as sample of the study from different bank branches. The results showed that, from the view point of questionnaireaudiences,factors such as causes beyond the banking factors, duty utilities, mismanagement andretaliatory behavior of borrowers, failure and negligence in obtaining sufficient collaterals, type of activity, transfer of received facilities by borrowers to other sectors, a history of cooperation of borrower with bank, and the inadequacy of the required financial resources are the most important factors influencing the non-repayment of quick yielding facilities in the branches of Melli bank of Shahrekord.

BarzegarandDiyanatiDeilami (2010), in a paper entitled "risk management model of received accounts", study risk factors in payment of received accounts in Iran. According to their article: no risk management model can be replaced with a suitable economic and legal system for collection of 
receivables.Reforms in law and the economic system, is the main condition for solving the problems of collection of receivables. In their article they examine the risks in received receivable accounts of Iran and answer to the question that, Is there sufficient and appropriate economical indicators to increase the productivity of information with regard to the payment system of Iran? The proposed model of this study is based on indicators of liquidity (current ratio, working capital ratio, quick ratio),cash flow indices (the ratio of cash flow, free cash flow ratio of 1 and 2),indicators of the solvency (leverage ratio, debt ratio, debt-to-equity ratio). The data has been gathered by the elimination sampling method (screening) from the financial statements of 117 companies listed in Tehran Stock Exchange,the date of their adoption relates to the years before 1388, and until 1391, their activities have continued, and the data has been analyzed using software SPSS.20.Finally, a local model is presentedto predict credibility claims of stock company's in Iran, and by use of which, companies can reduce the risk of receiving demands and consciously undertake more risks in certain circumstances.

\section{Research Hypothesis}

1. There is a significant relationshipbetween the degree of branch which gives facilities and the credit risk of customers.

2. There is a significant relationship between the amount ofreceived collaterals and credit risk of customers.

3. There is a significant relationship between the type ofreceived collaterals and credit risk of customers.

4. There is a significant relationship between granted interest rate and credit risk of customers.

5. There is a significant relationship between repayment time of granted facilities and credit risk of customers.

6. There is a significant relationship between the type of customers (real and legal) and credit risk of customers.

\section{Variables of the study}

The variables of this research are divided into two categories:

a) Independent variable

b) Dependent variable

Independent variables: Variables affecting the credit risk of real and legal customers, including the type of received collaterals from customers, amount of received collateral from clients,time of repayment for bank loans, the degree of branch which gives facilities,facilities rate and the type of customer (real or legal), whichwere extracted from claims and transactional files of Melli bank of Iran, in the southern branch of Tehran.

The dependent variable: credit risk in applicants of bank facilities and customers of Melli Bank of Iran, in the southern branches of Tehran, customer classification in terms of good and creditworthy customers without any debt or bad customers with outstanding debts.

\section{Hypothesis Analysis}

The results show that:

There isn't any significant relationship between time of repayment for facilities (bol.cot) and the dependent variable of the study, namely credit risk of Melli Bank customers of Iran in southern branches of Tehran. Because the resulting probability for long-term variable is $98 \%$, and for short term facilities this probability is $57 \%$, and it is not acceptable because it's higher than $10 \%$.

Type of customer variable (real- legal): Availability of (HA), with dependent variable of the study has a positive and significant relationship.Obtained coefficient for this variable is 3.47 , and its corresponding probability is 0.04 . Which is lower than $10 \%$, indicating that meanwhile with increasing the number of granted facilities for real individuals, default probability of facilities will be increased. And its final effective coefficient is 1.82 .

Kind of taken guarantee variable (SAFTEL) with dependent variable of the study has a positive and significant relationship. Obtained coefficient for this variable is 3.54 , and its corresponding probability is 0.07 . It is less than $10 \%$ and suggests that meanwhile by increasing the number of facilities that receive most of the guarantees in the form ofpromissory note, increases the probability of default facilities. The final effective coefficient is 1.33 .

The proportion of obtained guarantees variable (SANAD) with dependent variable of the study has a negative and significant relationship. Obtained coefficient for this variable is 13.92 , and its corresponding probability is 0.001 . It'sless than $5 \%$ and suggests that the reliability coefficient at $99 \%$,meanwhilewith the increasing ratio of estate collateral in the given decisions, default probability is drastically reduced. The final effective coefficient is6.49.

Real rate of granted facilities variable (REL (-1)) with dependent variable of the study has a positive and significant relationship. Obtained coefficient for this variable is 0.18 and its corresponding probability is 0.03 . It's less than $5 \%$ and suggests that the reliability coefficient at $95 \%$, meanwhile by increasing the 
difference in the facilities rate and the rate of inflation in a period before, the facility default probability increases. The final effective coefficient is 0.09 .

Branch degree variable (DEG) with dependent variable of the study has a positive and significant relationship. Obtained coefficient for this variable is 1.23 and its corresponding probability is 0.02 . It's less than $5 \%$ and suggests that the reliability coefficient at $95 \%$ meanwhile by increasing the degree of branch, the facility default probability increases. The final effective coefficient is 0.65 .

\section{Investigating the Power of Prediction in Accuracy of Model}

Another way which was used to check the efficiency of the model is investigation of the correct percentage in predicted probabilities by the use of fitted model.Table 4-5 in the statistical literature known as classification model, and it helps to assessing the amount of prediction and accuracy of model in classification of people. This table shows right and wrong based on principles of prediction.

In a proportion of observations $\mathrm{MOA}=1$ is predicted correctly, the degree of sensitivity in a ratio of observations is MOA $=0$ that have been predicted correctly, and it is so called detection level of model.To see the results in the table,at first cut value $(\mathrm{c}=0.5)$ should be identified here.It should be noted that, the cut-off point is the point which minimizes type I and type II errors, and is chosen exactly based on this basis. By defining cut-off point as 0.5 in assumption, customers whose default probability is more than 0.5 , are categorized as bad customers, and customers whose default probability is equal or less than 0.5 , are categorized as good customers. This model predicted 98 percent of good customers $(\mathrm{DEP}=0)$ correctly in the categorization of good customers, and predicted 98 percent of bad customers $(\mathrm{DEP}=1)$ correctly in the categorization of bad customers,and the function of 96 percent of customers by the use of this model is estimated properly.

Table 4-5:Table of predicting accuracy of model

\begin{tabular}{|l|l|l|l|}
\hline \multicolumn{4}{|c|}{ Success cutoff: C=0.5 } \\
\hline & \multicolumn{4}{|c|}{ Estimated Equation } \\
\hline & Dep=0 & Dep=1 & Total \\
\hline $\mathrm{P}(\mathrm{Dep}=1)<=\mathrm{C}$ & 69 & 3 & 72 \\
\hline $\mathrm{P}(\mathrm{Dep}=1)>\mathrm{C}$ & 1 & 25 & 26 \\
\hline Total & 70 & 28 & 98 \\
\hline Correct & 69 & 25 & 94 \\
\hline \% Correct & 98.57 & 89.29 & 95.92 \\
\hline \% Incorrect & 1.43 & 10.71 & 4.08 \\
\hline Total Gain* & -1.43 & 89.29 & 24.49 \\
\hline Percent Gain** & 98.57 & 89.29 & 85.71 \\
\hline
\end{tabular}

Also according to the table above, we find that in the fitted model the amount of the type I error, namely credit risk (classification of good customers among bad customers) is equal to $1.43 \%$, (it means number 1 minus degree of sensitivity)and the amount of type II error, namely commercial risk(classification of bad customers among good customers) is equal to $10.71 \%$, (it means number 1 minus degree of diagnosis).

\section{Conclusion}

The aim present study was attempting to find effective internal factors of organizations affecting the credit risk of banks and make a model for credit risk of facilities. Obviously if we can design a model that can predict the delayed or timely payment of facilities, associated risk with non-payment of facilities or in other words credit risk can be greatly controlled. To achieve the aforesaid goals, following assumptions were considered and somehow each of them includes some aspects of financial condition and customer's credit:

1. There is a significant relationshipbetween the degree of branch which gives facilities and the credit risk of customers.

2. There is a significant relationship between the amount ofreceived collaterals and credit risk of customers.

3. There is a significant relationship between the type ofreceived collaterals and credit risk of customers.

4. There is a significant relationship between granted interest rate and credit risk of customers.

5. There is a significant relationship between repayment time of granted facilities and credit risk of customers.

6. There is a significant relationship between the type of customers (real and legal) and credit risk of customers.

According to the hypothesis of the study, the obtained results in this study can be explained as follow:

There isn't a significant relationship between time of repayment for facilities and dependent variable of the study, namely credit risk of customers in Melli Bank of Iran, in northern branch of Tehran.

Type of customer variable (real- legal): Availability of (HA), with dependent variable of the study has a positive and significant relationship.Obtained coefficient for this variable is 1.82 , and its corresponding probability is 0.04 . That means, an increase of one percent to real customers, increases the possibility of non- 
repayment about 1.82 unit. These results are consistent and aligned with theoretical principles, because revocation of cheques and the deferred returns between real customers is more than legal customers.

Kind of taken guarantee variable (SAFTEL) with dependent variable of the study has a positive and significant relationship. Obtained coefficient for this variable is 1.33 , and its corresponding probability is 0.07. That means by an increase of one percent to guaranteed promissory note, the probability of non-repayment increases about 1.33 unit. These results are consistent and aligned with theoretical principles, because it can be observed, due to the weakness in liquidating of promissory notes, defers which are guaranteed by promissory notes will increase.

The proportion of obtained guarantees variable (SANAD) with dependent variable of the study has a negative and significant relationship. Obtained coefficient for this variable is -6.49 , and its corresponding probability is 0.001 . That means by an increase of one percent toestate collateral, the probability of nonrepayment decreases about 6.49 unit. These results are consistent and aligned with theoretical principles, because due to the possibility of liquidity in facilities which are guaranteed by immovable guarantees, they aren't differed, or are being receivable.

Real rate of granted facilities variable with dependent variable of the study has a positive and significant relationship. Obtained coefficient for this variable is 0.09 and its corresponding probability is 0.03 . That means by an increase of one percent to real rate of granted facilities, the probability of non-repayment increases about 0.09 units.

Branch degree variable with dependent variable of the study has a positive and significant relationship. Obtained coefficient for this variable is 0.65 and its corresponding probability is 0.02 . That means by an increase of one percent to the branch degree, the probability of non-repayment increases about 0.65 units. These results are consistent and aligned with theoretical principles, because in branches with a higher degree (smaller branches), number of employees and their quality is less than other cases.

Significant coefficients of the variables by using Wald statistic, and significance of general regression and well-fitted model, were approved by using LR statistics and HasmerLemsho at confidence level of 90.The predictive power of the model is approximately 89 . So the model has high capability and reliability in the estimation of credit risk. Significance and signs of coefficients in independent variables of the modelapproved the financial and economical theories in the field of determinant factors of credit risk.

The results show that taking collateral from clients is effective in preventing deferred facilities;so,bank officials should consider collateral as an important factor in granting facilities to applicants. Regarding types of collateral it can be said that, estate collateral and immovable ones have the greatest impact on reducing credit risk (non-repayment of loans).Repayment period cannot affect the credit risk of facilities.

\section{References}

[1] Armashi, M. (1390).Identifying effective variables on credit risk of real customers in Saman Bank (northern branch of the country).Master's thesis, University of Human Sciences.Payam Noor University, Behshahr.

[2] Barzegar, M.\&DiyanatiDeilami, Z. (1393). Risk management model and received accounts. Accounting Master's thesis.Tehran University of Economic Sciences.

[3] Heydarifar, S. (1390).Investigating effective factors on timely non-repayment of granted facilities in Melli Bank of Iran.Master's Thesis, School of Management, Tehran University.

[4] Khavari (1389).According to the Habibpour, H. (1392).Investigating factors affecting equipping bank resources: A Case study of Refah Bank in Isfahan.

[5] Ramezani (2006). . According to the Habibpour, H. (2013).Investigating factors affecting equipping bank resources: A Case study of Refah Bank in Isfahan.

[6] Tarfi, sh. (2006).Investigating the effect of size, type of industry and proportions of investment in predicting ability of facility repayment from the perspective of experts in Saderat Bank of Iran.Accounting MA thesis, School of Management, Tehran University.

[7] Falah Shams, M \&Mahdavi Rad, H. (2012).Design of validation model and predicting the credit risk of customers for leasingfacilities.Case Study: Iran Khodro leasing company, Economic Research, No. 44, spring 2012

[8] Mahmoudi, N. (2013). Investigating the causes and factors related to non-repayment of granted high efficiency facilities in the branches of Melli Bank of Shahrekord. MA thesis of Public Administration.Islamic Azad University, Isfahan branch

[9] Mousavi, A. (2010). Investigating the causes of deferred loans in EghtesadeNovin Bank during the years 1383 to 1388 in Tehran branches.Master's thesis, Tehran University.

[10] Yazdani\&Dehnavi.(2006). According to the Habibpour, H. (2013).Investigating factors affecting equipping bank resources: A Case study of Refah Bank in Isfahan.

[11] Gambera, M. (2000). "Simple Forecasts of Bank Loan in the Business Cycle", Emerging Issues Series, vol . 3, (April), pp. 1-27.

[12] Sylvester, I., Okpara, G.C. \& O. J. Chukwudi (2013), "Determinants of Loan Size and Repayment Performance of Small Oil Producers in Nigeria: The Case Study of Abia State", International Journal of Business Management and Administration, Vol. 2, No. 3, PP. 043-054.

[13] Wongnaa, C. A. \& D. Awonyu-Vitor (2013), "Factors Affecting Loan Repayment Performance among Yam Farmers in the Sene District, Ghana", Agris Online Papers in Economics, Vol. V, No. 2.

[14] Yenpao, Ch. Ruey-jiGuo\&Roa-Li Huang. (2009). Two stages credit evalution in bank loan appraisal؟ Economic Modelling 26: 6370. 